\title{
The Role of Angiogenesis in Colorectal Polyps and Cancer: a Review
}

\author{
Hamid Asadzadeh Aghdaei (MD) \\ Basic and Molecular Epidemiology of \\ Gastrointestinal Disorders Research \\ Center, Research Institute for \\ Gastroenterology and Liver Diseases, \\ Shahid Beheshti University of Medical \\ Sciences, Tehran, Iran \\ Zahra Pezeshkian (MSc) \\ Basic and Molecular Epidemiology of \\ Gastrointestinal Disorders Research \\ Center, Research Institute for \\ Gastroenterology and Liver Diseases, \\ Shahid Beheshti University of Medical \\ Sciences, Tehran, Iran \\ Meghdad Abdollahpour-Alitappeh \\ (PhD) \\ Larestan University of Medical \\ Sciences, Larestan, Iran \\ Ehsan Nazemalhosseini Mojarad \\ (PhD) \\ Gastroenterology and Liver Diseases \\ Research Center, Research Institute for \\ Gastroenterology and Liver Diseases, \\ Shahid Beheshti University of Medical \\ Sciences, Tehran, Iran \\ Mohammad Reza Zali (MD) \\ Gastroenterology and Liver Diseases \\ Research Center, Research Institute for \\ Gastroenterology and Liver Diseases, \\ Shahid Beheshti University of Medical \\ Sciences, Tehran, Iran \\ Corresponding author: Ehsan \\ Nazemalhosseini-Mojarad \\ Tel: + 9821-22432518 \\ E-mail: ehsanmojarad@gmail.com \\ Address: Research Institute for \\ Gastroenterology and Liver Diseases, \\ Shahid Beheshti University of Medical \\ Sciences, Yeman Street, Chamran \\ Expressway, Tehran, Iran \\ Received : 31 Dec 2017 \\ Revised: 01 Apr 2018 \\ Accepted: 09 Apr 2018 \\ Hamid Asadzadeh Aghdaei \\ https://orcid.org/0000-0002-9382-9840 \\ Ehsan Nazemalhosseini-Mojarad \\ https://orcid.org/0000-0001-8914-004X
}

\begin{abstract}
Colorectal cancer remains a leading cause of morbidity and mortality worldwide. Most colorectal cancers begin as a growth of tissue called a polyp, some types of which can change into cancer over the course of several years. Angiogenesis, the formation of new blood vessels, is known to play a key role in the initiation, growth and progression of polyp and colorectal cancer. In this review, we discuss the mechanisms involved in colorectal cancer and polyp angiogenesis.
\end{abstract}

Keywords: Colorectal Neoplasms, Polyps, Angiogenesis.

This paper should be cited as: Asadzadeh Aghdaei H, Pezeshkian Z, Abdollahpour-Alitappeh M, Nazemalhosseini Mojarad E, Zali MR, [The Role of Angiogenesis in Colorectal Polyps and Cancer: a Review]. mljgoums. 2018; 12(4):1-6 


\section{INTRODUCTION}

Colorectal cancer (CRC) is one of the most common cancers worldwide, accounting for approximately half a million deaths each year (1-3). The major risk factors for CRC include genetic predisposition and environmental factors, including smoking, physical inactivity, obesity and consumption of processed-meat and alcohol (4). These factors cause genetic and epigenetic changes, followed by transformation of normal colonic mucosa into invasive carcinoma (5). Colorectal polyps result from abnormal cell proliferation in the colorectal mucosa. According to histological and morphological features, colorectal polyps are divided into neoplastic (adenoma and carcinoma) and nonneoplastic (hyperplastic, hamartomatous and inflammatory) types (6). Neoplastic polyps, also known as adenomatous polyps, are subclassified by their histology appearance as tubular, villous and tubule-villous adenomas (7). Studies have demonstrated that villous adenomas account for approximately $5-10 \%$ of neoplastic polyps, most of which are suspected to have dysplasia. Approximately 10-15\% of neoplastic polyps show both morphological futures of villous and tubular types (7). Adenomatous polyps are not typically transformed to malignant cells, but characterization of the CRC features show that adenomatous polyps originate from the adenomatous polyps and adenoma-carcinoma sequence (3). In addition, some hyperplastic polyps demonstrated to have the potency of CRC initiation (8).

Common abnormalities associated with CRC include microsatellite instability (MSI), chromosomal instability (CIN) and the CpG island methylator phenotype $(9,10)$. MSI is a condition of genetic hypermutability resulting from impaired DNA mismatch repair system, accounting for approximately $15-20 \%$ of all CRC cases diagnosed (11). Importantly, 3-5\% of hereditary nonpolyposis CRC (HNPCC, a genetic disease of autosomal dominant inheritance) incidents result from a germ line mutation in the DNA mismatch repair genes, including $M S H 2, M L H 1, P M S 2, M L H 3$, MSH3, PMS1 and Exo1. Meanwhile, 15\% of sporadic MSI tumors have been reported to undergo hyper-methylation in the promoter region of MLHI (11). CIN, the most common cause of genomic instability in CRC, is characterized by gain or loss of whole chromosomes or chromosomal regions harboring genes, leading to activation of oncogenes (such as K-ras, cSrc and c-myc) and inactivation of tumor suppressor genes (such as adenomatous polyposis coli, $\mathrm{P}_{53}$ and hetrozigosity for the long arm of chromosome 18) (12-14). The $\mathrm{CpG}$ island methylator phenotype is another cause of tumorigenesis characterized by the hypermethylation of CPG islands located at promoter regions, resulting in missregulated activity of the tumor suppressors or oncogenes $(11,15)$.

Cancer cells secrete growth factors capable of promoting the formation of new blood vessels (angiogenesis), which is involved in tumorigenesis and cancer cell growth. The two mechanisms for the formation of new blood vessel can be categorized into vasculogenesis (the formation of first primitive vascular plexus de novo) and angiogenesis (the formation of new vessels from preexisting vessels) $(16,17)$. Angiogenesis is an essential process in cancer progression, in which vascular endothelial growth factors (VEGFs) play a critical role (9). There is increasing evidence showing that cancer cells are major sources of VEGF (18). In this review, we discuss the mechanisms involved in CRC and polyp angiogenesis, angiogenesis regulation and therapeutic methods for angiogenesis inhibition.

\section{Search strategy}

A literature search strategy was performed for all English literature published before 2018. The search was carried out using electronic databases including PubMed, Embase, Scopus and Web of Sciences. The following keywords were used in the search strategy: 'colorectal cancer', 'epidemiology', 'incidence', 'mortality', 'risk factor', 'survival', 'Polyp', and 'VEGF-A'.

\section{Angiogenesis}

Angiogenesis is a complex process that facilitates the delivery of nutrients and oxygen to cells by formation of new blood vessels. This process plays an important role in cancer development by promoting tumor growth and metastasis (19). It involves proliferation of activated endothelial cells, migration of the endothelial cells to remote targets, assembly of endothelial cells into new capillary tubes, followed by the synthesis of a new basement 
membrane and maturation of vessels with the formation of a vascular lumen (20). There is accumulating evidence suggesting that a variety of molecular pathways involved in angiogenesis may have therapeutic potentials.

\section{Angiogenesis factors}

Both vasculogenesis and angiogenesis are regulated by precise balance between the proangiogenic and anti-angiogenic factors (16). Angiogenic growth factors and cytokines include VEGF, fibroblast growth factor (FGF), tumor necrosis factor-alpha (TNF- $\alpha$ ), TGF- $\beta$ and angiopoietins (Angs) (21). In addition, several signaling pathways including VEGF, Notch/delta, Ephrins/Ephs, semaphorin/plexin/neuropilin, Slit-Robo hedgehog and Sprouty are involved in the initiation and progression of angiogenesis (22).

\section{VEGF}

VEGFs play an important role in the regulation of tumor angiogenesis. The VEGF family includes VEGF-A, VEGF-B, VEGF-C, VEGF-D, placental growth factor (PGF), VEGF-E (Orf-VEGF) and Trimeresurus flavoviridis svVEGF (23).

Hypoxia is widely recognized as a key driving force for tumor angiogenesis via induction of VEGF and other direct-acting angiogenic factors. In addition, VEGF expression and secretion increase following activation of hypoxia-inducible factor 1-alpha (HIF-1 alpha, a subunit of a heterodimeric transcription factor HIF-1) in hypoxic conditions (24). The biological effects of VEGF are mediated by VEGF receptors (VEGFR), which are devided into three main subtypes: VEGFR-1, VEGFR-2 and VEGFR-3. These receptors may be membrane-bound or soluble depending on alternative splicing, and can bind to VEGF isoforms $(24,25)$.

VEGFR-1 binds to VEGF-B and PGF and exerts a positive regulatory effect on angiogenesis (26). VEGFR-2, which binds to VEGF-A, also has a pro-angiogenic function and enhances endothelial cell proliferation, migration and invasion. VEGF-C and VEGF$\mathrm{D}$ bind to VEGFR-3, which mainly mediates lymphangiogenesis $(19,26)$.

\section{Role of Ang in Angiogenesis}

Tie-1 and Tie-2 tyrosine kinase receptors expressed specifically on vascular endothelial cells are essential for vascular maturation during developmental, physiological and pathological angiogenesis. Angs-1-4 have been identified as bona fide ligands for the Tie-2 receptor, while Tie-1 remains an orphan receptor capable of heterodimerization with Tie-2 and modulating Tie-2 signal transduction (27). Ang-1, Ang-2 and Ang-4 were demonstrated to play an important role in angiogenesis and metastasis in cancer. While Ang-1 is widely expressed in normal adult tissues, Ang-2 is expressed in a variety of human malignancies, including carcinomas of the colon, liver, stomach, lung and thyroid, as well as malignant gliomas (2835). In addition to normal cells, Ang-1 is expressed in tumor cells and binds to Tie1 and Tie2 on the vascular endothelial cells (27). Ang-2 is expressed on endothelial cells and binds to the Tie-1 and Tie-2 receptors. Moreover, VEGF-A, platelet-derived growth factor, insulin like growth factor and other proangiogenic factors stimulate Ang/Tie signaling and lead it to angiogenesis $(27,36)$.

\section{Clinical Data of VEGFs}

Binding of VEGF-A to VEGFR-2 and regulation of angiogenesis enhance endothelial cell proliferation, migration and survival. Elevated levels of VEGF-A have been detected in some cancers such as CRC and breast cancer (26). Some studies have shown that decreased expression of VEGFR-1 in tumors was correlated with decreased survival rate and high-stage disease in pancreatic cancer (39). The expression of VEGF along with VEGFR-1 and VEGFR-2 in tumor cells has been demonstrated. it has been recently reported that VEGF, VEGFR-1 and VEGFR-2 are significantly overexpressed in adenomacarcinomas and serrated adenomas when compared with hyperplastic polyps $(40,41)$.

VEGF-B enhances survival of endothelial and smooth muscle cells, and up-regulates the expression of pro-survival genes. Overexpression of VEGF-B in some cancers, such as ovarian, colorectal, renal and prostate cancer is thought to be correlated with disease stage and expression of VEGFR-1 $(42,43)$.

VEGF-C expression is associated with advanced metastatic CRC, and VEGF-D plays a role in lymph angiogenesis and lymphatic metastasis. Both VEGF-C and VEGF-D bind to VEGFR-2 and VEGFR-3 (26). These 
clinical data could be useful for finding a suitable anti-angiogenic therapy for CRC patients.

\section{Anti-angiogenic therapy}

In 1971, Folkman described the therapeutic implications of tumor angiogenesis and the concept of tumor angiogenesis. Based on their mechanism of action, there are four approaches for anti-angiogenic therapy, including blockage of the angiogenic factors or receptors such as VEGF and VEGFRs, direct inhibition of proliferation or survival of endothelial cells, prevention of extracellular matrix and basal membrane degradation, as well as inhibition of vascular cellular adhesion molecules, such as integrin $\alpha v \beta 3$ (44). The most common therapies include blocking endogenous tumor VEGF expression, preventing VEGF binding and its signal transduction, and neutralizing VEGF in the microvascularization process. Targeting VEGF expression by Bevacizumab is a notable treatment approach for CRC $(26,45,46)$. Bevacizumab is a recombinant human monoclonal antibody that directly targets synthesis of VEGF during tumor growth, decreasing angiogenic cell signaling and blood supply for tumors. The drug is usually used in combination with chemotherapeutic drugs for patients with metastatic CRC. Studies suggest that this therapeutic approach can improve patients' survival rate by almost five months $(26,45)$.

Aflibercept is a recombinant fusion protein that binds to VEGFR-1, VEGFR-2 and PIGF in tumor xenograft models. This protein prevents angiogenesis and growth of new and established tumors and decreases vessel density, blood flow and risk of metastasis. Aflibercept also has negative effects on hypoxia-induced angiogenesis $(47,48)$.

\section{REFERENCES}

1. Cappell MS. Pathophysiology, clinical presentation, and management of colon cancer. Gastroenterol Clin North Am. 2008; 37: 124.https://doi.org/10.1016/j.gtc.2007.12.002

2. Safaee A, Moghimi-Dehkordi B, Fatemi SR, Ghiasi S, Nemati-Malek F, MR Zali. Characteristics of colorectal mucinous adenocarcinoma in Iran. Asian Pac J Cancer Prev. 2010; 11(5): 1373-5.

3. Shussman N, Steven DW. Colorectal polyps and polyposis syndromes. Gastroenterol Rep. 2014; 2(1): 115. https://doi.org/10.1093/gastro/got041.
NCT01120288, NCT01210222 and NCTO1193868 are some preventing agents for other angiogenesis regulators such as HIF-1 alpha, Ang-1 and Ang-2, as well as the Notch signaling pathway (26). Aflibercept is also known as VEGF-Trap, and serves as VEGF decoy receptor that binds to circulating VEGFs and inhibits the activity of VEGF-A and VEGF-B. Same events can occur in the case of PGF, which inhibits the growth of new blood vessels.

Application of tyrosine kinase inhibitors (TKIs) is another approach to block angiogenesis. TK receptors including VEGFR, FGFR and platelet-derived growth factor receptor are thought to play a key role in angiogenesis and are involved in multiple signaling pathways. TKIs such as Imatinib, Sorafenib, Sunitinib, Pazopanib and Axitinib bind to the ATP binding site and inhibit the activation of more than one receptor, resulting in angiogenesis blockage (49).

\section{CONCLUSION}

Angiogenesis plays an important role in tumor growth, malignancy, migration and metastasis. Since most CRCs derive from adenomas, finding molecular mechanisms and effective factors in polyps and tumor angiogenesis provides a clear insight into the development of polyps and cancer cells and progression to malignancy.

\section{ACKNOWLEDGEMENTS}

We would like to thank the staff of the Gastroenterology and Liver Disease Research Center at Shahid Beheshti University of Medical Sciences, Tehran, Iran.

\section{CONFLICT OF INTEREST}

All contributing authors declare no conflict of interest.

\footnotetext{
5. Center MM, Jemal A, Ward E. International trends in colorectal cancer incidence rates. Cancer Epidemiology Biomarkers Prev. 2008; 18(6): 168894.https://doi.org/10.1158/1055-9965.EPI-09-0090

6. Leslie A, Carey FA, Steele RJ. The colorectal adenoma-carcinoma sequence. Br J Surg. 2002; 89(7): 845-60.https://doi.org/10.1046/j.13652168.2002.02120.x

7. NL B, Kalkbrenner KA, Merchea A, Dozois EJ, Landmann RG, De Petris G, et al. Colectomy for endoscopically unresectable polyps: how often is it cancer?. Dis Colon Rectum. 2012; 55(11): 1111-6. https://doi.org/10.1097/DCR.0b013e3182695115
} 
8. Liljegren A, Lindblom A, Rotstein S, Nilsson B, Rubio C, Jaramillo E. Prevalence and incidence of hyperplastic polyps and adenomas in familial colorectal cancer: correlation between the two types of colon polyps. Gut. 2003; 52(8): 11407.https://doi.org/10.1136/gut.52.8.1140

9. Sam Al-Sohaily, Andrew Biankin, Rupert Leong, Maija Kohonen-Corish, Warusavitarne J. Molecular pathways in colorectal cancer. JGH. 2012; 27(9): 142331. https://doi.org/10.1111/j.1440-1746.2012.07200.x

10. Guinney J, Dienstmann R, Wang X, de Reyniès A, Schlicker A, Soneson C, et al. The consensus molecular subtypes of colorectal cancer. Nat Med. 2015; 21: 13506. https://doi.org/10.1038/nm.3967

11. Mundade R, Imperiale TF, Prabhu L, Loehrer PJ, Lu T. Genetic pathways, prevention, and treatment of sporadic colorectal cancer. Oncoscience. 2014; 1(6): 400-6. https://doi.org/10.18632/oncoscience.59

12. Pino MS, Chung DC. The chromosomal instability pathway in colon cancer. Gastroenterology. 2010; 138(6): 2059-72.

14. Armaghany T, Wilson JD, Chu Q, Mills G. Genetic Alterations in Colorectal Cancer. Gastrointest Cancer Res. 2012; 5(1): 19-27.

15. Nazemalhosseini Mojarad E, Kuppen PJK, Asadzadeh Aghdaei H, MR Zali. The CpG island methylator phenotype (CIMP) in colorectal cancer. Gastroenterology and Hepatology From Bed to Bench. 2013; 6(3): 120-8.

16. Distler JH, Hirth A, Kurowska-Stolarska M, Gay RE, Gay S, Distler O. Angiogenic and angiostatic factors in the molecular control of angiogenesis. Q J Nucl Med. 2003; 47(3): 149-61.

17. Johnson KE, Wilgus TA. Vascular Endothelial Growth Factor and Angiogenesis in the Regulation of Cutaneous Wound Repair. Adv Wound Care. 2014; 3(10): 647-61. https://doi.org/10.1089/wound.2013.0517 18. Masoumi Moghaddam, Amini A, Morris DL, Pourgholami MH. Significance of vascular endothelial growth factor in growth and peritoneal dissemination of ovarian cancer. Cancer Metastasis Rev. 2012; 31(1-2): 143-62.https://doi.org/10.1007/s10555-011-9337-5

19. Martins SF, Garcia EA, Luz MA, Pardal F, Rodrigues M, Filho AL. Clinicopathological correlation and prognostic significance of VEGF-A, VEGF-C, VEGFR-2 and VEGFR-3 expression in colorectal cancer. Cancer Genomics Proteomics. 2013; 10(2): 55-67.

20. Pang RW, Kojiro M. Clinical implications of angiogenesis in cancers. Vasc Health Risk Manag. 2006; 2(2): 97-108. https://doi.org/10.2147/vhrm.2006.2.2.97

21. Ucuzian AA, Gassman AA, East AT, Greisler HP. Molecular mediators of angiogenesis. J Burn Care Res. 2010; 31(1): $\quad$ 158-75. https://doi.org/10.1097/BCR.0b013e3181c7ed82

22. Siekmann AF, Lawson ND. Notch signalling and the regulation of angiogenesis. Cell Adh Migr. 2007; 1(2): 104-6.https://doi.org/10.4161/cam.1.2.4488

23. Shibuya M. Vascular Endothelial Growth Factor (VEGF) and Its Receptor (VEGFR) Signaling in Angiogenesis: A Crucial Target for Anti- and ProAngiogenic Therapies. Genes Cancer. 2011; 2(12): 1097105.https://doi.org/10.1177/1947601911423031
24. Simiantonaki N, Taxeidis M, Jayasinghe C, Kirkpatrick CJ. Epithelial expression of VEGF receptors in colorectal carcinomas and their relationship to metastatic status. Anticancer Res. 2007; 27(5A): 324550.

25. Ellis LM, Hicklin DJ. VEGF-targeted therapy: mechanisms of anti-tumour activity. Nat Rev Cancer. 2008; 8(8): 579-91. https://doi.org/10.1038/nrc2403

25. Ellis LM, Hicklin DJ. VEGF-targeted therapy: mechanisms of anti-tumour activity. Nat Rev Cancer. 2008; 8(8): 579-91. https://doi.org/10.1038/nrc2403

26. Sun W. Angiogenesis in metastatic colorectal cancer and the benefits of targeted therapy. $\mathrm{J}$ Hematol Oncol. 2012; 5: 63. https://doi.org/10.1186/1756-8722-5-63

27. Fagiani E, Christofori G. Angiopoietins in angiogenesis. Cancer Lett. 2013; 328(1): 18-26. https://doi.org/10.1016/j.canlet.2012.08.018

28. Ahmad SA, Liu W, Jung YD, Fan F, Reinmuth N, Ellis LM, et al. Differential expression of angiopoietin-1 and angiopoietin-2 in colon carcinoma. A possible mechanism for the initiation of angiogenesis. Cancer. 2001; 92: 1138 -43. https://doi.org/10.1002/10970142(20010901)92:5<1138::AID-CNCR1431>3.0.CO;2$\mathrm{L}$

29. Tanaka S, Mori M, Sakamoto Y, Makuuchi M, Sugimachi K, Wands JR. Biologic significance of angiopoietin-2 expression in human hepatocellular carcinoma. J Clin Invest. 1999; 103(3): 341-5. https://doi.org/10.1172/JCI4891

30. Etoh T, Inoue H, Tanaka S, Barnard GF, Kitano S, Mori M. Angiopoietin 2 is related to tumor angiogenesis in gastric carcinoma: possible in vivo regulation via induction of proteases. Cancer Res. 2001; 61(5): 214553.

31. Wong MP, Chan SY, Fu KH, Leung SY, Cheung N, Yuen ST, et al. The angiopoietins, tie 2 and vascular endothelial growth factor are differentially expressed in the transformation of normal lung to non-small cell lung carcinomas. Lung Cancer. 2000; 29(1): 11-22. https://doi.org/10.1016/S0169-5002(00)00118-5

32. Bunone G, Vigneri P, Mariani L, Buto S, Collini P, Pilotti S, et al. Expression of angiogenesis stimulators and inhibitors in human thyroid tumors and correlation with clinical pathological features. AmJ Pathol. 1999; 155(6): 1967-76.https://doi.org/10.1016/S00029440(10)65515-0

33. Stratmann A, Risau W, Plate KH. Cell type-specific expression of angiopoietin-1 and angiopoietin-2 suggests a role in glioblastoma angiogenesis. Am J Pathol. 1998; 153(5): 1459-66.

https://doi.org/10.1016/S0002-9440(10)65733-1

34. Holash J, Maisonpierre PC, Compton D, Boland P, Alexander CR, Zagzag D, et al. Vessel cooption, regression, and growth in tumors mediated by angiopoietins and VEGF. Science. 1998; 284(5422): 1994-8.https://doi.org/10.1126/science.284.5422.1994

35. Koga K, Todaka T, Morioka M, Hamada J, Kai Y, Yano S, et al. Expression of angiopoietin-2 in human glioma cells and its role for angiogenesis. Cancer Res. 2001; 61(16): 6248-54. 
36. Huang H BA, Woodnutt G, Lappe R. Targeting the ANGPT-TIE2 pathway in malignancy. Nat Rev Cancer. 2010; 10(8): 575-85.https://doi.org/10.1038/nrc2894

37. Kofler NM, Shawber CJ, Kangsamaksin T, Reed HO, Galatioto J, Kitajewski J. Notch Signaling in Developmental and Tumor Angiogenesis. Genes Cancer. 2011; 2(12): 1106-16.

https://doi.org/10.1177/1947601911423030

38. Siekmann AF, Lawson ND. Notch Signalling and the Regulation of Angiogenesis. Cell Adh Migr. 2007; 1(2): 104-6. https://doi.org/10.4161/cam.1.2.4488

39. Hanrahan V, Currie MJ, Gunningham SP, Morrin $\mathrm{HR}$, Scott PA, Robinson $\mathrm{BA}$, et al. The angiogenic switch for vascular endothelial growth factor (VEGF)-A, $V E G F-B, V E G F-C$, and VEGF-D in the adenomacarcinoma sequence during colorectal cancer progression. J Pathol. 2003; 200(2): 183-94. https://doi.org/10.1002/path.1339

40. Taba M, Nakayama T, Naito S, Mihara Y, Miura S, Naruke Y, et al. Differential Expression of Vascular Endothelial Growth Factor (VEGF) and VEGF Receptors in the Sequence of Hyperplastic Polyp, Serrated Adenoma and Adenocarcinoma of Colorectum. Acta Med. 2008; 53(4): 85-8.

41. Pezeshkian Z, Forouzesh F, Peyravian N, YaghoobTaleghani M, Asadzadeh-Aghdaei H, Zali MR, et al. Clinicopathological correlations of VEGF-A and MMP-7 genes expression in different types of colorectal adenoma polyps. WCRJ. 2017; 4(4): e978.
42. Zhang F, Tang Z, Hou X, Lennartsson J, Li Y, Koch $\mathrm{AW}$, et al. VEGF-B is dispensable for blood vessel growth but critical for their survival, and VEGF-B targeting inhibits pathological angiogenesis. Proc Natl Acad Sci U S A. 2009; 106(15): 6152-7. https://doi.org/10.1073/pnas.0813061106.

43. WC Pang $\mathrm{R}$ TPR. Clinical Implications of Angiogenesis in Cancers. Vasc Health Risk Manag. 2006; 2(2): 97-108. https://doi.org/10.2147/vhrm.2006.2.2.97

44. Sang Hun Lee, Dongjun Jeong, Yong-Seok Han, Baek MJ. Pivotal role of vascular endothelial growth factor pathway in tumor angiogenesis. Ann Surg Treat Res. $\quad 2015 ; \quad$ 89(1): $1-8$. https://doi.org/10.4174/astr.2015.89.1.1

45. Ehsan NazemalhosseiniMojarad, Kuppen PJ. HER2 and immunotherapy using monoclonal antibodies in colorectal cancer. IMT. 2013; 5(12): 1267-9.

46. Gaya A, V T. A preclinical and clinical review of aflibercept for the management of cancer. Cancer Treat Rev. 2012; 38(5): 484-93. https://doi.org/10.1016/j.ctrv.2011.12.008 47. Ciombor KK, Berlin J. Aflibercept-a Decoy VEGF Receptor. Curr Oncol Rep. 2014; 16(2): 368. https://doi.org/10.1007/s11912-013-0368-7

48. Al-Husein B1 AM, Trepte M, Deremer DL, Somanath PR. Antiangiogenic therapy for cancer: an update. Pharmacotherapy. 2012; 32(12): 1095-111. https://doi.org/10.1002/phar.1147 